\title{
Influence of subcellular metal compartmentalization in different prey on the transfer of metals to a predatory gastropod
}

\author{
Mashan Cheung, Wen-Xiong Wang*
}

Atmospheric, Marine, Coastal Environment Program, and Department of Biology, The Hong Kong University of Science and Technology (HKUST), Clear Water Bay, Kowloon, Hong Kong SAR

\begin{abstract}
Marine snails Thais clavigera accumulate high metal concentrations in their bodies and trophic transfer may play an important role in metal bioaccumulation in this top predator in the intertidal rocky shore. In this study, we examined the relationship between the subcellular metal distribution in prey (barnacles, mussels, oysters, herbivorous snails, limpets) and the assimilation efficiency (AE) of cadmium, silver and zinc in T. clavigera. The metal subcellular distributions in the oyster prey were also modified and the metal AEs in T. clavigera measured. We further purified the subcellular fractions of different prey and determined how the biochemical properties of different fractions affected the metal AEs. Results showed that the AEs of each metal from different prey were comparable and generally high (50 to $90 \%$ ). Significant positive correlation was found between the Cd AEs and the metallothionein-like protein (MTLP) fraction, and between the AEs of Zn and the trophically available metal (TAM) fraction. For Ag, no relationship between its AE and any of the subcellular fractions was documented. When $T$. clavigera fed on oysters with different exposure regimes, the metal AEs were not significantly correlated with the metal subcellular partitioning in the oysters. Furthermore, the AEs of Ag, Cd and Zn were similar among the different biochemical fractions. For these 3 metals, T. clavigera assimilated 60 to $85 \%$ from the insoluble fraction, 40 to $80 \%$ from the heatsensitive protein fraction, 45 to $90 \%$ from the MTLP fraction, and 40 to $80 \%$ from the metal-rich granule (MRG) fraction. Our results imply that metals bound to the insoluble fraction or MRG were also bioavailable to $T$. clavigera. This study may help to better understand the mechanisms of metal transfer along the intertidal food chain.
\end{abstract}

KEY WORDS: Whelks $\cdot$ Metals $\cdot$ Subcellular compartment $\cdot$ Trophic transfer $\cdot$ Assimilation

Resale or republication not permitted without written consent of the publisher

\section{INTRODUCTION}

Marine invertebrates take up metals via 2 routes: uptake from water across permeable membranes such as the gills, and the uptake of dietary borne metals (i.e. trophic transfer, Wang 2002). Previously, dissolved uptake was assumed to be a dominant route for metal uptake, and water quality criteria were established based on such a premise. In recent years, increasing evidence has shown that dietary uptake of metals should be incorporated into the overall bioaccumulation of metals by aquatic animals (Reinfelder et al. 1998, Wang \& Fisher 1999, Clearwater et al. 2002).
Among the different trace metals/metalloids, it is generally thought that $\mathrm{Hg}$ and perhaps Cs can be biomagnified along marine food chains, but other metals such as Se and $\mathrm{Zn}$ also have the potential of being biomagnified along specific food chains (Wang 2002). The ability of metals to be transferred along food chains mainly depends on the detoxification mechanisms at the lower trophic levels (Wallace \& Lopez 1997).

Two different strategies are mainly involved in the detoxification of metals by aquatic animals (Viarengo \& Nott 1993), including metals bound to special proteins (i.e. metallothioneins, MT) (Roesijadi 1992, 1996, Klaassen et al. 1999), and metals bound to granules 
such as the metal-rich granule (MRG). Different metal detoxification pathways play different roles in the trophic transfer of metals along food chains. There has been considerable interest in how the metal subcellular distribution in prey organisms affects the assimilation efficiency by predators, as well as the role that each subcellular fraction plays in the trophic transfer of metals (Wallace \& Luoma 2003, Wallace et al. 2003). Several studies have shown that MRG is non-bioavailable to the higher trophic levels (Nott 1989, 1990, Nott \& Nicolaidou 1993), and that metals bound to cytosolic fractions are critical for their transfer to higher trophic levels and for assimilation (Ettajani et al. 2001). For predatory invertebrates, metals bound to cytosolic fractions of prey worms are highly bioavailable to grass shrimps (Wallace et al. 1998, Wallace \& Luoma 2003). Wallace \& Luoma (2003) recently proposed that $\mathrm{Cd}$ partitioned in the trophically available fraction (a combination of organelles, heat-sensitive proteins such as HSP enzymes, and heat-stable protein or metallothionein-like protein MTLP) of the bivalve Potamocorbula amurensis was assimilated at an efficiency close to $100 \%$ by the predator, the grass shrimp Palaemon macrodatylus. This definition of trophically available metal (TAM) certainly offers a rather simple and straightforward approach to predicting the trophic transfer of metal pollutants in marine predators, but there is currently a dearth of information for other metals and predators to further confirm this hypothesis.

The control of 'metal speciation' in prey organisms in controlling their bioavailability to the grazers/predators in marine systems has generated much interest over the past decade (Reinfelder \& Fisher 1991, Wang 2002, Xu \& Wang 2002). In marine phytoplankton, it has been shown that metal distributed in the cytoplasmic fraction is more highly bioavailable to marine herbivores such as copepods and bivalves than metals bound to cell walls/membranes (Reinfelder \& Fisher 1991, Wang \& Fisher 1996, Chong \& Wang 2000, Xu \& Wang 2001). There is also a substantial need to understand the influences of different 'metal speciation' in prey on the trophic transfer of metals to marine predators. In this study, we examined the transfer of 3 metals $(\mathrm{Cd}, \mathrm{Ag}, \mathrm{Zn})$ in a marine rocky shore food chain comprised of different prey (barnacles, bivalves, snails, limpets) and a top predator (the whelk Thais clavigera). We specifically investigated the importance of different subcellular metal distributions in the prey in controlling the assimilation efficiency of the top predator in this specific food chain. Previous studies showed that $T$. clavigera accumulated metals predominantly from their prey (Blackmore 2000, Blackmore \& Wang 2004), and that metal assimilation can be exceedingly high, which may lead to the potential biomagnification of a few metals in this specific food chain (Wang 2002).
T. clavigera is an important key predator which is widely distributed in many rocky intertidal shores (Abe 1989). These animals can accumulate high metal concentrations in their bodies (Han et al. 1997, Hung et al. 2001, Blackmore \& Wang 2004). Five different prey including the oyster Saccostrea glomerata, the herbivorous snail Monodonta labio, the barnacle Balanus amphitrite, the limpet Crepidula onyx, and the black mussel Septifer virgatus were considered, all of which are generally preyed on by $T$. clavigera in the field (Tong 1986, Abe 1994). Furthermore, we conducted experiments to examine the assimilation of each metal subcellular fraction from the prey, in an attempt to directly assess the roles of different subcellular fractions in the transfer of metals to the intertidal rocky shore top predator.

\section{MATERIALS AND METHODS}

Collection of snails and prey. The whelk Thais clavigera was collected from the rocky shores of the Hong Kong University of Science and Technology. The prey of whelks including the oyster Saccostrea glomerata and the herbivorous snail Monodonta labio were also collected from the same location. The barnacle Balanus amphitrite was collected at the pier at Hebe Haven, the limpet Crepidula onyx from Tolo Harbour, and the black mussel Septifer virgatus from Clear Water Bay. These prey were maintained in the laboratory and fed with different phytoplankton foods. The whelks were fed with a mixture of different prey for 1 to $2 \mathrm{wk}$ before the experiments were conducted. There were considerable differences in trace metal concentrations in these prey species, with barnacles and oysters generally containing the highest $\mathrm{Cd}$ and $\mathrm{Zn}$ concentrations, whereas the concentrations in mussels and limpets were the lowest (M. Cheung \& W.-X. Wang unpubl. data).

Radiolabeling of prey. The prey were radiolabeled with radiotracers by feeding on radiolabeled diatoms or exposure to dissolved radioisotopes. The diatom Thalassiosira weissflogii was radiolabeled with ${ }^{110 \mathrm{~m}} \mathrm{Ag}$ (in $0.1 \mathrm{~N} \mathrm{HNO}_{3}$, from Riso National Laboratory, Denmark), ${ }^{109} \mathrm{Cd}$ (in $0.1 \mathrm{~N} \mathrm{HCl}$, from New England Nuclear) and ${ }^{65} \mathrm{Zn}$ (in $0.1 \mathrm{~N} \mathrm{HCl}$, from the Oak Ridge National Laboratory), as described in Wang \& Fisher (1996). Briefly, exponentially growing diatoms were filtered from their growth medium and radiolabeled with $74 \mathrm{kBq} \mathrm{l}^{-1}$ of ${ }^{110 \mathrm{~m}} \mathrm{Ag}$ and ${ }^{109} \mathrm{Cd}_{\text {, and }} 111 \mathrm{kBq} \mathrm{l^{-1 }}$ of ${ }^{65} \mathrm{Zn}$. After $6 \mathrm{~d}$ of radiolabeling, the diatoms were filtered and resuspended in filtered seawater, and were then fed to the different prey (for barnacles, limpets, mussels, oysters) for a total of $4 \mathrm{~d}$. The herbivorous snail Monodonta labio was radiolabeled following $14 \mathrm{~d}$ 
aqueous exposure to $74 \mathrm{kBq} \mathrm{l}{ }^{-1}$ of ${ }^{110 \mathrm{~m}} \mathrm{Ag},{ }^{109} \mathrm{Cd}$ and ${ }^{65} \mathrm{Zn}$. After exposure, the animals were first evacuated of their ingested radiolabeled food for $12 \mathrm{~h}$. Three individuals from each species were then measured for their subcellular metal distributions (described below), and the remaining individuals were dissected before their digestive glands were fed to the whelks.

Metal assimilation from prey. After radiolabeling, the prey were dissected and the digestive glands of herbivorous snails, limpets, mussels and oysters fed to the whelks. The digestive glands were chosen as food because they were selectively consumed by whelks in the field (Tong 1986). Due to their small size, the whole body of the barnacles was fed to the whelks. The radiolabeled prey were placed in $250 \mathrm{ml}$ of filtered seawater. The 8 tagged whelks were subsequently individually placed in the beaker and allowed to feed for $1 \mathrm{~h}$, after which the whelks were immediately rinsed with $0.22 \mu \mathrm{m}$ of filtered seawater and radioassayed. The whelks were then individually transferred into $250 \mathrm{ml}$ of seawater to depurate their ingested radiolabeled foods, while they were fed with nonradiolabeled mussel tissues daily. Water was changed every $12 \mathrm{~h}$, and the feces were collected to minimize the recycling of metals and to measure the gut passage time of the ingested food materials. The radioactivity was assayed at 3 to $12 \mathrm{~h}$ intervals over the $48 \mathrm{~h}$ depuration periods. Assimilation efficiencies (AEs) were determined as the percentage of initial radioactivity retained in Thais clavigera after $48 \mathrm{~h}$ of depuration (Blackmore \& Wang 2004).

Feeding rate effects on metal assimilation. The oysters Saccostrea glomerata were radiolabeled by feeding on the radiolabeled diatom Thalassiosira weissflogii and the digestive glands were dissected out as described above. The digestive glands were weighed before being placed in a $500 \mathrm{ml}$ beaker. Fifteen Thais clavigera were then placed into the beakers and allowed to feed for $1 \mathrm{~h}$, after which time any remaining oyster tissue was removed and weighed. The ingestion rate of the whelks was calculated from the prey consumed divided by the weight of whelk tissue. The whelks were subsequently radioassayed and the AEs were measured as described above.

Metal assimilation from oysters with different exposure regimes. AEs of $\mathrm{Ag}, \mathrm{Cd}$ and $\mathrm{Zn}$ of whelks fed on oysters with different exposure regimes were determined. The oysters Saccostrea glomerata were either exposed previously to the radiolabeled diatom Thalassiosira weissflogii or exposed to radioisotopes in the dissolved phase for different times. For the dietary exposure, the diatoms were radiolabeled as described above, and oysters were fed with the radiolabeled diatoms for $12 \mathrm{~h}$ (short-term exposure) or $14 \mathrm{~d}$ (longterm exposure). For long-term exposure, the water was changed after $2 \mathrm{~h}$ of radioactive feeding each day. For the dissolved phase exposure, the oysters were exposed to radiolabeled seawater for $12 \mathrm{~h}$ (short-term exposure) or $14 \mathrm{~d}$ (long-term exposure) during which the radiolabeled seawater was changed daily. Radioisotopes additions were $51.8 \mathrm{kBq} \mathrm{l}^{-1}$ each for ${ }^{110 \mathrm{~m}} \mathrm{Ag},{ }^{109} \mathrm{Cd}$ and ${ }^{65} \mathrm{Zn}$ for both treatments of dietary exposure, and were $77.7 \mathrm{kBq} \mathrm{l}{ }^{-1}$ each for ${ }^{110 \mathrm{~m}} \mathrm{Ag},{ }^{109} \mathrm{Cd}$ and ${ }^{65} \mathrm{Zn}$ for the 2 dissolved phase exposure treatments. No food was provided during the radiolabeling period in the dissolved exposure treatments. After radiolabeling, the oysters were dissected into 2 parts comprising the digestive glands and other soft tissues, which were placed in $250 \mathrm{ml}$ of filtered seawater. Eight tagged whelks were then individually placed into the beaker. After $1 \mathrm{~h}$ of radioactive feeding, the animals were radioassayed and the AE was determined after $48 \mathrm{~h}$ of depuration. Three individual oysters from each treatment were also measured for their metal subcellular distributions in digestive gland and other soft tissues (described below).

Assimilation from pure subcellular fractions of prey. Barnacles, herbivorous snails and oysters were radiolabeled with ${ }^{110 \mathrm{~m}} \mathrm{Ag},{ }^{109} \mathrm{Cd}$ and ${ }^{65} \mathrm{Zn}$ by feeding on radiolabeled diatoms as described above. All the soft tissues were then dissected out and separated into different cellular fractions as described by Wallace et al. (1998) with a slight modification. Briefly, the soft tissues of barnacles, oysters, and herbivorous snails were homogenized and centrifuged at $1500 \times g$ for $15 \mathrm{~min}$ at $4^{\circ} \mathrm{C}$. The pellets contained the metalrich granule (MRG) and the cellular debris fractions. The supernatant resulting from the first centrifugation was further centrifuged at $100000 \times g$ for $1 \mathrm{~h}$, and the pellet was defined as the organelle fraction. By combining the MRG, cellular debris and organelles, this fraction was defined as the insoluble fraction (Fig. 1). After heat treatment, the supernatant (defined as the soluble fraction) was centrifuged again, which resulted in 2 fractions including the metallothionein-like protein (MTLP) fraction (supernatant), and the heat-sensitive protein (i.e. HSP enzyme) (pellet). The different subcellular fractions (insoluble, HSP, MTLP) were freeze-dried and mixed with a gelatin solution to form gelatin cubes before being fed to the whelks (Wallace et al. 1998). Wallace et al. (1998) showed that the Cd AE from the whole tissues of worms was comparable to that from the worm tissue imbedded in the gelatin. After $1 \mathrm{~h}$ of radioactive feeding, the AEs of the whelks fed with the different subcellular fractions of prey were measured after a $48 \mathrm{~h}$ depuration period, using the methods described above.

Since a few studies have shown that the metals bound to the cellular debris fraction are also bioavail- 


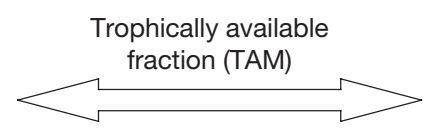

\begin{tabular}{|c|c|c|c|c|}
\hline $\begin{array}{c}\text { Metal rich } \\
\text { granule } \\
\text { (MRG) }\end{array}$ & $\begin{array}{c}\text { Cellular } \\
\text { debris }\end{array}$ & Organelle & $\begin{array}{c}\text { Heat } \\
\text { Sensitive } \\
\text { Protein } \\
\text { (HSP) }\end{array}$ & $\begin{array}{c}\text { Metallo- } \\
\text { thionein } \\
\text {-like protein } \\
\text { (MTLP) }\end{array}$ \\
Insoluble fraction & Soluble fraction
\end{tabular}

Fig. 1. Metal subcellular fractions identified in this study and terms used to quantify different combinations of subcellular fractions

able to the predator (Wallace \& Lopez 1997, Rainbow et al. 2004), another experiment was conducted to directly measure the metal AEs from the MRG fraction. The herbivorous snail Monodonta labio and the oyster Saccostrea glomerata were radiolabeled with ${ }^{110 \mathrm{~m}} \mathrm{Ag}$, ${ }^{109} \mathrm{Cd}$ and ${ }^{65} \mathrm{Zn}$ by feeding on radiolabeled diatoms as described above. After the first centrifugation at $1500 \times$ $g$ for $15 \mathrm{~min}, \mathrm{NaOH}$ was added to the pellet and heated at $80^{\circ} \mathrm{C}$ for $10 \mathrm{~min}$, and centrifuged at $5000 \times g$ again for $10 \mathrm{~min}$ at $4^{\circ} \mathrm{C}$. The pellet was the MRG fraction and the supernatant was the cellular debris fraction. The MRG fraction was solidified in the gelatin solution (1.2 $\mathrm{g}$ of gelatin and $10 \mathrm{ml}$ of filtered seawater). The mixture of gelatin and MRG was placed at $-20^{\circ} \mathrm{C}$ for $15 \mathrm{~min}$, and the gelatin cubes were fed to the whelks. After $1 \mathrm{~h}$ of radioactive feeding, the AEs of the whelks were quantified.

Metal subcellular distribution in the prey and whelks. The subcellular distributions of ${ }^{110 \mathrm{~m}} \mathrm{Ag},{ }^{109} \mathrm{Cd}$ and ${ }^{65} \mathrm{Zn}$ in the prey and whelks' whole soft tissues were determined using the methods described by Wallace et al. (1998). A total of 5 different fractions were obtained, including the cellular debris, MRG, organelle, HSP and MTLP fractions. The summation of the HSP, MTLP and organelles was defined as the trophically available metal (TAM) (Fig. 1), while the summation of cellular debris and the MRG was defined as the trophically unavailable metal (Wallace \& Luoma 2003). The summation of the MRG, cellular debris and the organelle fractions was defined as the insoluble fraction, and the summation of HSP and MTLP was the soluble fraction (Fig. 1). All 5 fractions were radioassayed for ${ }^{110 \mathrm{~m}} \mathrm{Ag},{ }^{109} \mathrm{Cd}$ and ${ }^{65} \mathrm{Zn}$ to allow estimation of the distribution of these metals.

Radioactivity measurements and statistical analysis. Radioactivity was measured using a Wallac $1480 \mathrm{NaI}$

Table 1. Thais clavigera. Assimilation efficiencies (AE, \%) of $\mathrm{Ag}, \mathrm{Cd}$ and $\mathrm{Zn}$ in whelks feeding on different prey in different experiments. Mean \pm SD $(n=8)$

\begin{tabular}{|c|c|c|c|c|}
\hline \multirow[t]{2}{*}{ Experiment } & \multirow[t]{2}{*}{ Prey/Exposure/Fraction } & \multicolumn{3}{|c|}{$\mathrm{AE}(\%)$} \\
\hline & & $\mathrm{Ag}$ & $\mathrm{Cd}$ & $\mathrm{Zn}$ \\
\hline \multirow[t]{5}{*}{ Expt 1: Different prey (digestive glands) } & Balanus amphitrite & $60.9 \pm 10.7$ & $76.2 \pm 10.4$ & $53.1 \pm 7.5$ \\
\hline & Crepidula onyx & $81.3 \pm 9.8$ & $94.1 \pm 5.1$ & $87.3 \pm 7.4$ \\
\hline & Monodonta labio & $80.2 \pm 15.8$ & $92.1 \pm 5.1$ & $90.7 \pm 7.7$ \\
\hline & Saccostrea glomerata & $64.1 \pm 20.6$ & $81.6 \pm 2.9$ & $85.1 \pm 10.9$ \\
\hline & Septifer virgatus & $60.9 \pm 10.7$ & $81.9 \pm 7.2$ & $92.3 \pm 10.8$ \\
\hline \multicolumn{5}{|l|}{ Expt 2: Exposure regime } \\
\hline \multirow[t]{4}{*}{ Digestive gland of oyster } & $12 \mathrm{~h}$ dietary & $59.6 \pm 13.2$ & $88.7 \pm 12.2$ & $82.1 \pm 16.0$ \\
\hline & $14 \mathrm{~d}$ dietary & $61.7 \pm 15.6$ & $94.2 \pm 7.0$ & $68.0 \pm 11.5$ \\
\hline & $12 \mathrm{~h}$ dissolved & $86.3 \pm 7.3$ & $91.8 \pm 6.3$ & $86.3 \pm 7.3$ \\
\hline & 14 d dissolved & $65.7 \pm 15.7$ & $92.3 \pm 3.4$ & $72.3 \pm 14.5$ \\
\hline \multirow[t]{4}{*}{ Other soft tissue of oyster } & $12 \mathrm{~h}$ dietary & $87.2 \pm 17.5$ & $91.8 \pm 4.7$ & $91.5 \pm 7.4$ \\
\hline & 14 d dietary & $78.7 \pm 19.8$ & $89.9 \pm 15.5$ & $87.3 \pm 9.2$ \\
\hline & $12 \mathrm{~h}$ dissolved & $65.8 \pm 27.8$ & $81.2 \pm 15.6$ & $73.1 \pm 21.3$ \\
\hline & $14 \mathrm{~d}$ dissolved & $74.2 \pm 16.4$ & $84.0 \pm 8.4$ & $77.2 \pm 15.0$ \\
\hline \multicolumn{5}{|l|}{ Expt 3: Pure subcellular fraction } \\
\hline Balanus amphitrite & Insoluble fraction & $75.9 \pm 15.0$ & $67.6 \pm 17.5$ & $75.1 \pm 14.6$ \\
\hline \multirow[t]{4}{*}{ Monodonta labio } & Insoluble fraction & $85.3 \pm 9.8$ & $64.0 \pm 18.6$ & $79.6 \pm 12.0$ \\
\hline & Heat-sensitive protein & $63.2 \pm 21.3$ & $81.4 \pm 27.0$ & $79.4 \pm 4.9$ \\
\hline & MTLP & $83.1 \pm 11.3$ & $84.2 \pm 16.5$ & $79.4 \pm 4.9$ \\
\hline & Metal-rich granules & $38.8 \pm 7.3$ & $66.7 \pm 17.3$ & $44.4 \pm 7.8$ \\
\hline \multirow[t]{4}{*}{ Saccostrea glomerata } & Insoluble fraction & $63.7 \pm 11.4$ & $72.7 \pm 12.6$ & $74.0 \pm 11.1$ \\
\hline & Heat-sensitive protein & $41.7 \pm 18.1$ & $80.5 \pm 26.3$ & $69.0 \pm 15.4$ \\
\hline & MTLP & $43.8 \pm 16.3$ & $67.4 \pm 24.8$ & $70.6 \pm 11.7$ \\
\hline & Metal-rich granules & $60.0 \pm 12.7$ & $70.9 \pm 20.9$ & $60.7 \pm 9.1$ \\
\hline
\end{tabular}


(T1) gamma detector. The gamma emission of ${ }^{109} \mathrm{Cd}$ was determined at $88 \mathrm{keV},{ }^{110 \mathrm{~m}} \mathrm{Ag}$ at $658 \mathrm{keV}$, and ${ }^{65} \mathrm{Zn}$ at $1115 \mathrm{keV}$. Statistical analysis was carried out by appropriate post hoc tests or $t$-tests. All percentage data were arcsine-transformed, tested for homogeneity of variance and normal distribution before statistical analysis. Regression analysis was also conducted to test for the correlation between the metal AEs and different subcellular fractions.

\section{RESULTS}

\section{Metal assimilation from prey}

The retention of $\mathrm{Ag}, \mathrm{Cd}$ and $\mathrm{Zn}$ following pulse feeding of different radiolabeled prey is show in Fig. 2.

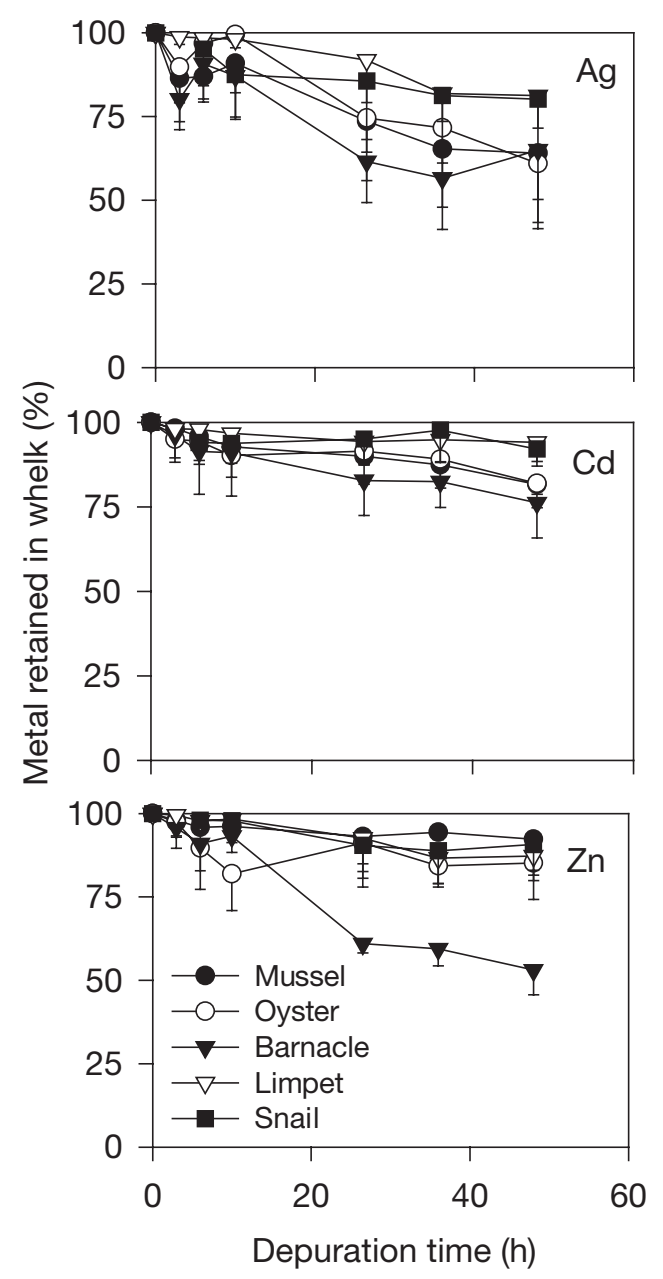

Fig. 2. Thais clavigera. Retention of $\mathrm{Ag}, \mathrm{Cd}$ and $\mathrm{Zn}$ in whelks following pulse feeding of radiolabeled prey. Prey included the mussel Septifer virgatus, the oyster Saccostrea glomerata, the barnacle Balanus amphitrite, the herbivorous snail Monodonta labio and the limpet Crepidula onyx. Mean \pm SD $(\mathrm{n}=8)$

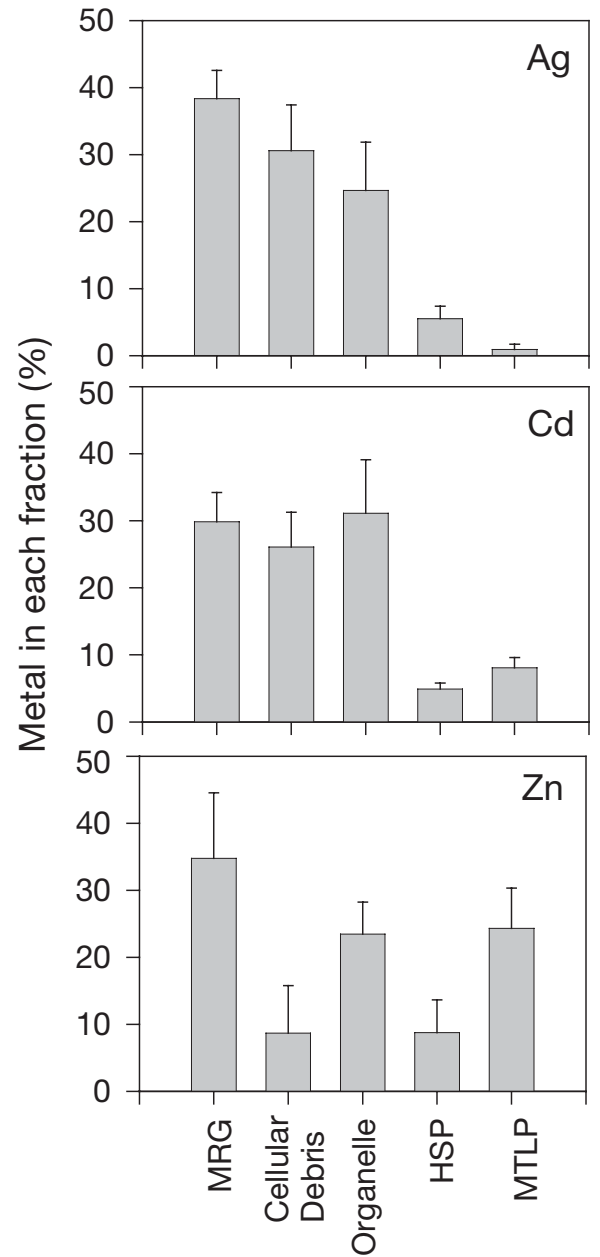

Fig. 3. Thais clavigera. Subcellular distributions of Ag, Cd and $\mathrm{Zn}$ in whelks after assimilation of ingested radiolabeled oysters. Mean \pm SD $(n=8)$. MRG: metal-rich granule; HSP: heat-sensitive protein; MTLP: metallothionein-like protein

A very high retention of the 3 metals was observed for all prey. The AEs were calculated as the percentage of metals retained in the whelks after $48 \mathrm{~h}$ of depuration (Table 1), and ranged from 53 to $94 \%$ for all 3 metals and for the 5 species of prey. Within each prey treatment, there was rather large individual variability in the quantified AE for each metal. The AEs for Ag were generally the lowest among the 3 metals. Among the 5 prey, the AEs of metals from the barnacles were also generally lower than from the other prey (digestive glands), especially for Zn. The AEs were comparable among the other prey species. After depuration, the subcellular distribution of the assimilated metals in the whelks was quantified (Fig. 3); thus, the main subcellular pool of assimilated Ag was the insoluble fraction (MRG + cellular debris + organelle). About 38\% of Ag was bound with the MRG fraction and only $1 \%$ of Ag was bound to the MTLP fraction. For Cd, 30\% was bound to the MRG fraction and $8 \%$ was bound to the 
MTLP fraction. The subcellular distribution of $\mathrm{Zn}$ in the whelk was markedly different from Ag and Cd. About 35 and $24 \%$ of Zn was bound to the MRG and MTLP fractions, respectively; thus, both fractions were important in binding with $\mathrm{Zn}$.

The whole prey tissue was also fractionated to determine the metal partitioning in different subcellular fractions (Fig. 4). Among the 5 prey, most metals were
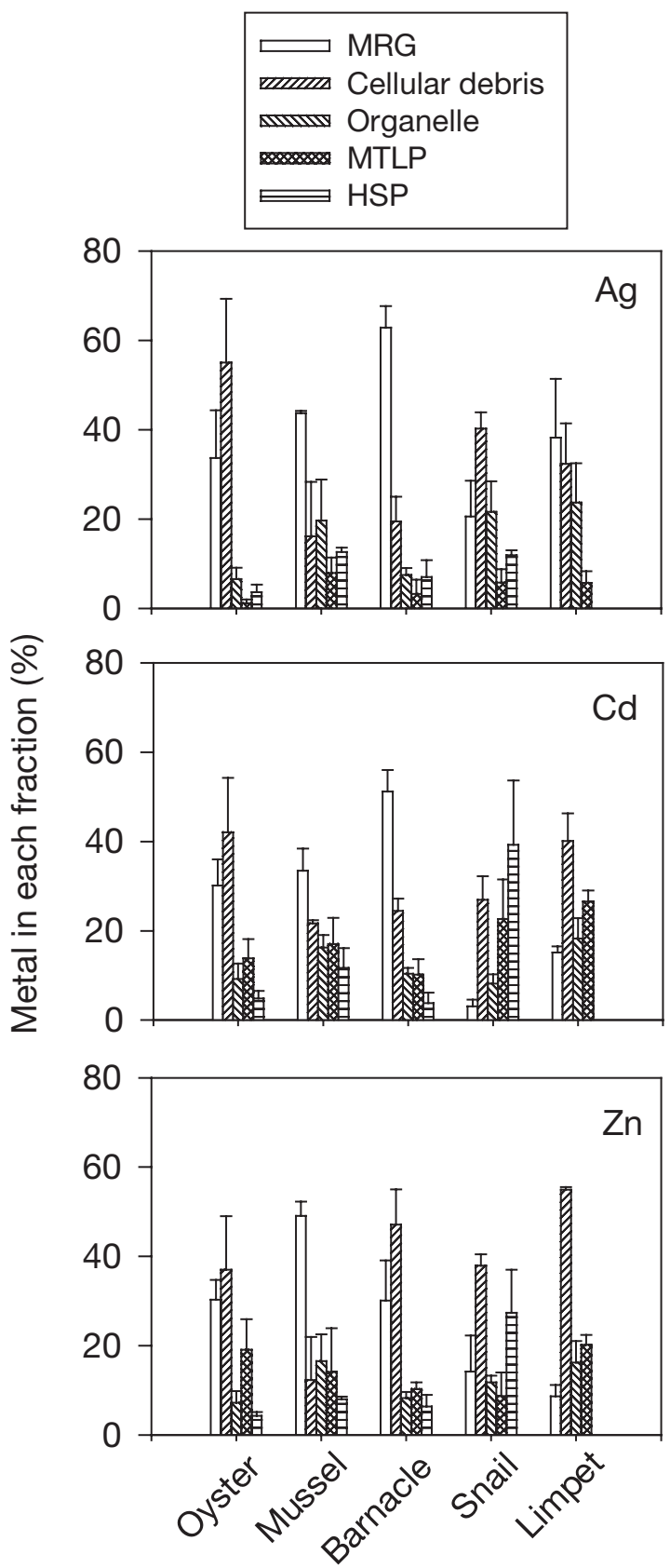

Fig. 4. Subcellular distributions of radiolabeled $\mathrm{Ag}, \mathrm{Cd}$ and $\mathrm{Zn}$ in the oyster Saccostrea glomerata, the mussel Septifer virgatus, the barnacle Balanus amphitrite, the herbivorous snail Monodonta labio and limpet Crepidula onyx. Mean $\pm \mathrm{SD}$

$$
(\mathrm{n}=8)
$$

distributed in the MRG + cellular debris fractions (after the first centrifugation). For the 2 bivalve species (oysters and mussels), MRG and cellular debris (oysters only) were the 2 dominating pools for metal storage. Similarly, most of the metals assimilated by the barnacles were deposited in the MRG and cellular debris fractions, and MRG was the dominating pool for $\mathrm{Cd}$ and Ag storage. In contrast, most of the assimilated $\mathrm{Cd}$ in the herbivorous snail Monodonta labio was bound to the soluble fractions (HSP and MTLP fractions). The HSP fraction was also important for Ag and $\mathrm{Zn}$ storage in this snail species. For limpets, the MRG + cellular debris was the dominating pool for all metal storage, but the MTLP fraction was also important for $\mathrm{Cd}$ and Zn sequestration. When the metal AEs were correlated with the metal distribution in different subcelluar fractions of the prey, there was a significant positive relationship between the $\mathrm{Cd} \mathrm{AE}$ and the percentage of $\mathrm{Cd}$ in the MTLP fraction (Table 2). No correlation was found for other combinations of metal and each subcellular fraction. The metal AEs were then further correlated with the TAM fraction (organelles + HSP + MTLP) (Fig. 5). A significant correlation between the $\mathrm{AE}$ and the TAM fraction was documented for $\mathrm{Zn}$, but not for $\mathrm{Cd}$ and Ag. When all 3 metals were considered together, a significant correlation was also evident. There was no significant correlation between the metal AE and the percentage of soluble or insoluble fractions (Table 2).

\section{Feeding rate effects on metal assimilation}

The feeding rate of individual whelks was calculated after $1.5 \mathrm{~h}$ of radioactive feeding on the radiolabeled oysters, and the AE of different individuals was calcu-

Table 2. Thais clavigera. Correlation coefficients $\left(\mathrm{r}^{2}\right)$ between the metal assimilation efficiency (AE) of whelks and the percentage of metals distributed in different subcellular fractions of the prey. The trophically available metal fraction (TAM = organelles + heat-stable protein [HSP] + metallothionein-like protein [MTLP]), soluble (HSP + MTLP), and insoluble fraction (metal-rich granule [MRG] + cellular debris + organelle) are also considered in the correlation analysis. Significant correlations are indicated (bold). ${ }^{*} \mathrm{p}<0.05$

\begin{tabular}{|lccc|}
\hline Fraction & Ag AE & Cd AE & Zn AE \\
\hline MRG & 0.447 & 0.588 & 0.167 \\
Cellular debris & 0.203 & 0.280 & 0.001 \\
Organelle & 0.428 & 0.317 & 0.099 \\
HSP & 0.041 & 0.002 & 0.024 \\
MTLP & 0.047 & $\mathbf{0 . 9 0 9}^{*}$ & 0.251 \\
TAM & 0.397 & 0.245 & $\mathbf{0 . 7 4 7}$ \\
Soluble fraction & 0.004 & 0.119 & 0.359 \\
Insoluble fraction & 0.001 & 0.119 & 0.559 \\
\hline
\end{tabular}




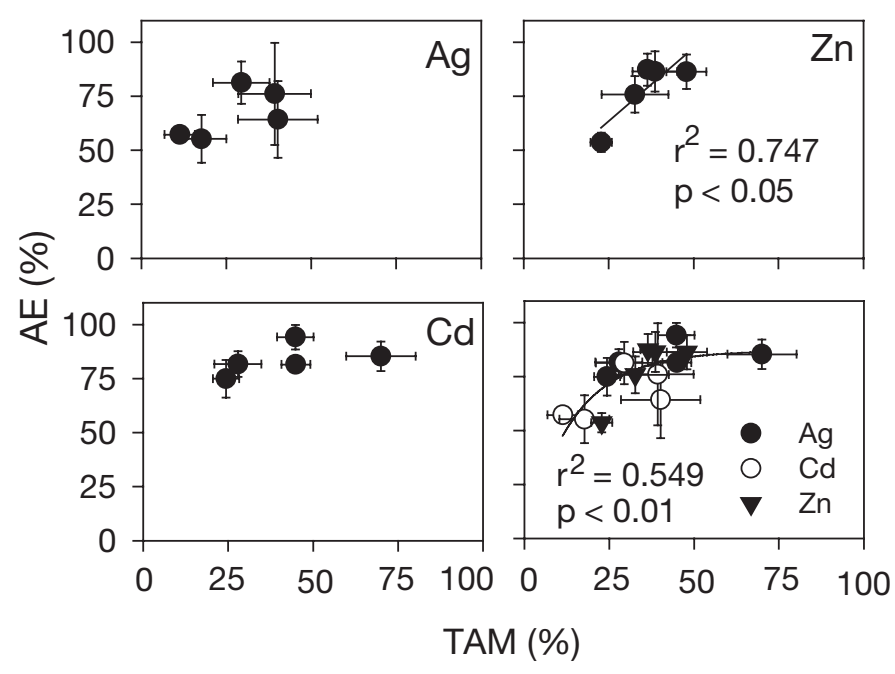

Fig. 5. Thais clavigera. Relationships between the metal assimilation efficiency (AE) of whelks and its percentage in the trophically available metal (TAM) fraction among different prey. Mean \pm SD $(n=8)$. The equation describing the relationship between $\mathrm{Zn} \mathrm{AE}$ and TAM is $\mathrm{AE}=29.3+1.36 \mathrm{TAM}$, and the equation describing the relationship between the AEs of all 3 metals and their TAM is AE $=88\left(1-\mathrm{e}^{-0.067 \mathrm{TAM}}\right)$

lated after $48 \mathrm{~h}$ of depuration. Feeding rates of individual whelks ranged between 2.8 and $23.4 \%$ of body dry weight each day, and the AEs ranged from 10 to $84 \%$ for Ag, 24 to $86 \%$ for $\mathrm{Cd}$, and 27 to $95 \%$ for $\mathrm{Zn}$. There was no significant relationship between the feeding rate and the $\mathrm{AE}$ of metals in the whelks (data not shown). However, it appeared that the metal AEs were reduced substantially at the highest feeding rate (23.4\% of body dry weight each day, in which the AEs of $\mathrm{Ag}, \mathrm{Cd}$ and $\mathrm{Zn}$ were as low as 32, 31 and $36 \%$, respectively). The gut passage time (GPT) of whelks was measured by continuously radioassaying the produced feces and ranged between 22 and $46 \mathrm{~h}$. There was no significant relationship between the AEs of metals and their respective GPTs.

\section{Metal assimilation for oysters with different exposure regimes}

Depuration of ingested metals by Thais clavigera fed on oyster tissues that were radiolabeled with different exposure pathways for different times is indicated in Fig. 6. Retention of metals was generally comparable among different treatments. The calculated AEs for whelks fed with digestive glands of radiolabeled oysters were 60 to $86 \%$ for $\mathrm{Ag}$, 89 to $94 \%$ for $\mathrm{Cd}, 68$ to $86 \%$ for $\mathrm{Zn}_{\text {; }}$ and for whelks fed with the other soft tissues of oysters 66 to $87 \%$ for $\mathrm{Ag}$, 81 to $92 \%$ for Cd, and 73 to $92 \%$ for Zn (Table 1). There was no significant difference in metal AEs from the radiolabeled oysters with different exposure routes and times (post hoc tests). When comparing the metal AEs feeding on the digestive gland and other soft tissues, the Ag AEs were somewhat lower from the digestive gland with dietary exposure. In this experiment, there was no significant correlation between the metal AE and the percentage of TAM fraction or the percentage of the soluble fraction for either digestive glands or the other soft tissue fed to the whelks.

\section{Assimilation from pure subcellular fractions of prey}

The percentages of $\mathrm{Ag}, \mathrm{Cd}$ and $\mathrm{Zn}$ retained in the whelks after ingestion of pure subcellular fractions of barnacles, oysters and herbivorous snails are shown in Fig. 7. For barnacles, only a small portion of metals was partitioned in the TAM fraction, and the radioactivity of this fraction was too low for the experiments. Only the insoluble fraction (cellular debris + MRG + organelle fractions) was, therefore, collected in this experiment. The percentage retained in the whelk body was similar when the animals fed on different

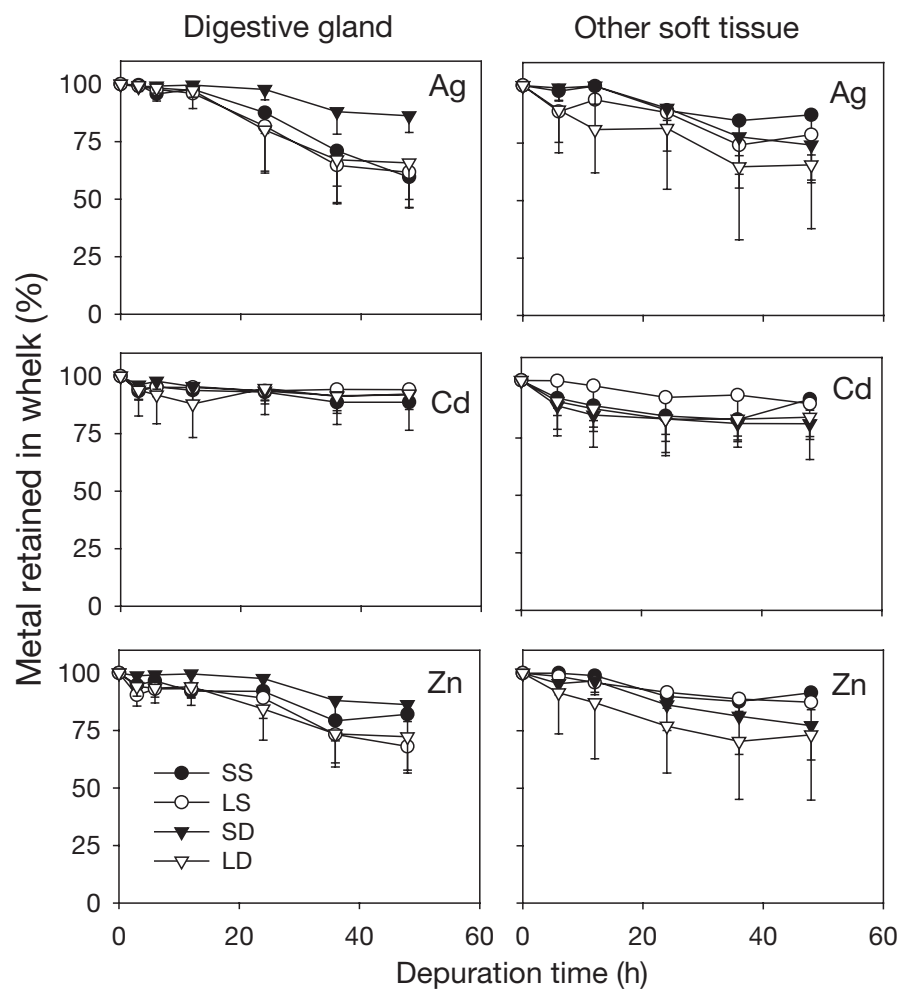

Fig. 6. Thais clavigera. Retention of $\mathrm{Ag}, \mathrm{Cd}$ and $\mathrm{Zn}$ in whelks following pulse feeding of oyster prey radiolabeled with different exposure regimes. SS: $12 \mathrm{~h}$ dietary exposure; LS: $14 \mathrm{~d}$ dietary exposure; SD: $12 \mathrm{~h}$ dissolved exposure; LD: $14 \mathrm{~d}$ dissolved exposure. Mean $\pm \mathrm{SD}(\mathrm{n}=8)$ 


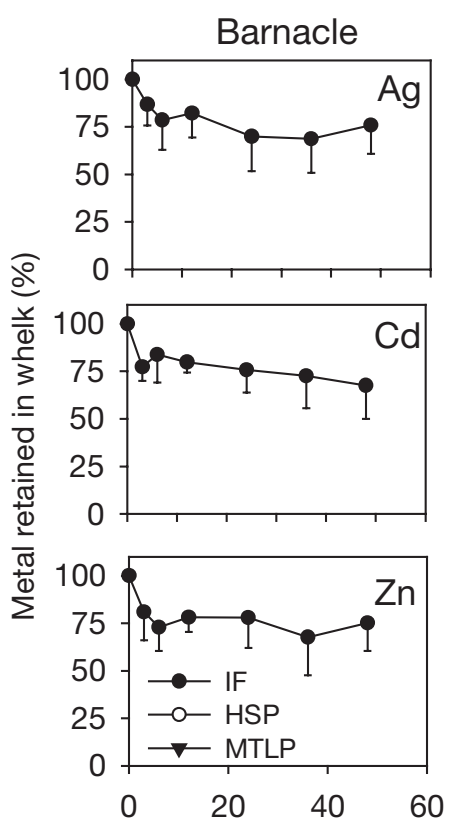

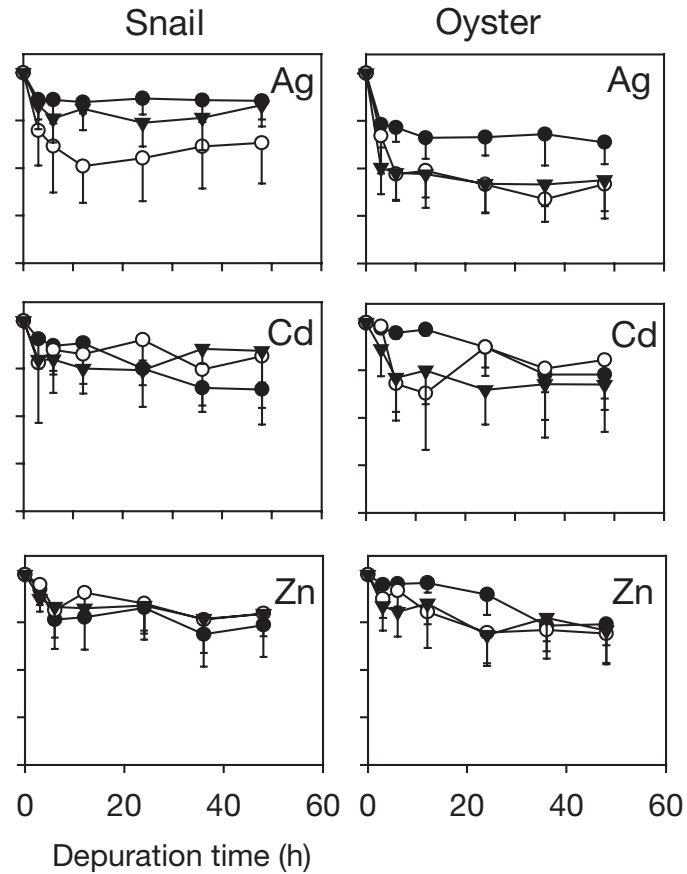

Fig. 7. Thais clavigera. Retention of $\mathrm{Ag}, \mathrm{Cd}$ and $\mathrm{Zn}$ in whelks following pulse feeding of a radiolabeled subcellular fraction from the barnacle Balanus amphitrite, the snail Monodonta labio and the oyster Saccostrea glomerata. IF: insoluble fraction; HSP: heatsensitive protein; MTLP: metallothionein-like protein. Mean \pm SD $(n=8)$

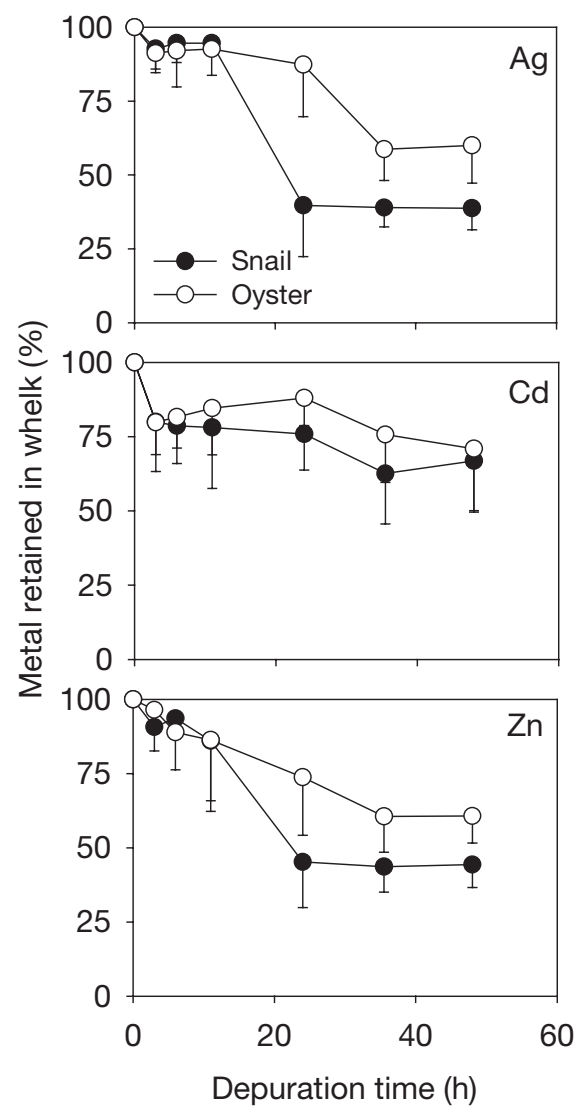

Fig. 8. Thais clavigera. Retention of $\mathrm{Ag}, \mathrm{Cd}$ and $\mathrm{Zn}$ in whelks following pulse feeding of radiolabeled metal-rich granules from the snail Monodonta labio and the oyster Saccostrea glomerata. Mean \pm SD $(\mathrm{n}=8)$ subcellular fractions of prey. For whelks fed on the snail subcellular fractions, the AEs of all 3 metals were comparable among the 3 different fractions (Table 1). For whelks fed on the insoluble fraction of barnacles, the AEs for Ag, Cd and $\mathrm{Zn}$ were as high as 68, 76 and $75 \%$, respectively (Table 1). In general, the metal AEs for the insoluble fraction of different prey were comparable to those for the HSP and MTLP fractions, indicating that metals bound to the insoluble fraction were equally bioavailable to the whelks.

In another experiment, the MRG fraction of snails and oysters were directly purified and fed to the whelks for metal AE measurement (Fig. 8). Our results show that the metals bound to the MRG fraction were also available to the whelks. The AEs of metals from the MRG fraction were lower than those from the insoluble fraction in whelks feeding on Monodonta labio. For oysters, however, the AEs were comparable to those measured for the insoluble fraction.

\section{DISCUSSION}

\section{Assimilation from different prey}

Several studies have quantified the trophic transfer of metals in marine predatory snails (Nott \& Nicolaidou 1994, Wang \& Ke 2002, Blackmore \& Wang 2004). One area that has drawn recent attention is how the different metal subcellular distributions in prey organisms affect the trophic transfer of metals 
along food chains (Wallace \& Lopez 1996, Ettajani et al. 2001, Wallace \& Luoma 2003, Wallace et al. 2003). Two main pathways are involved in metal detoxification, including the inducible metal binding proteins such as MT (Roesijadi 1992, 1996, Klaassen et al. 1999), and the metal-rich granules (MRGs) (Rainbow 1993). Both metal sequestrations allow animals to detoxify the metals, but have contrasting effects on the trophic transfer of metals. Wallace et al. (1998) suggested that metals associated with the cytosolic fraction (HSP + MTLP) and the organelle fraction of the oligochaete Limndrilus hoffmeisteri were most available to the omnivorous shrimp Palaemonetes pugio. Metals associated with phosphate granules (MRG) in prey are not bioavailable to predators (Nott 1989, Nott et al. 1993), whereas metals associated with MRG, mainly composed of carbonate, may be partly available to the predatory snail Nassarius reticulatus (Nott 1989).

The 5 species of prey in our study were chosen because they are commonly found along Hong Kong rocky shores, and are components in the diet of Thais clavigera (Tong 1986). Among these 5 prey, the barnacles had the highest percentage of metals distributed in the insoluble fraction, and the MRG pathway was the main pathway for barnacles to detoxify the accumulated metals (Rainbow 1987). Most Ag was distributed in the insoluble fraction of the prey's soft tissues as a result of its high affinity for the insoluble ligands. For $\mathrm{Cd}$, a higher percentage was bound to the soluble fraction in the prey's soft tissues, presumably because $\mathrm{Cd}$ induced the production of $\mathrm{MT}$ (Klaassen et al. 1999). Our study suggests that the AEs for the whelks fed on different prey were similar, but were much lower for whelks fed on barnacles because the MRG was the main binding ligand for the metals in the barnacles. As MRG was less bioavailable to the predators, the AEs for whelks consuming barnacles would be lower. The herbivorous snails Monodonta labio had the highest percentage of metal distributed in the TAM fraction among the 5 prey species, and correspondingly, the AEs for whelks fed on this snail were generally high. In addition, our data showed a significant relationship between the AEs, and the $\mathrm{Cd}$ and $\mathrm{Zn}$ distribution in the whelk's prey. The positive significant correlation between the $\mathrm{Cd} \mathrm{AE}$ and the percentage of $\mathrm{Cd}$ in the MTLP fraction suggested a high bioavailability of the MTLP fraction. The AE of Zn increased with the percentage of metals deposited in the TAM; thus, this fraction was more bioavailable to the whelks than the other fractions.

Nevertheless, there was no significant correlation between the Ag AE and any of its subcellular fractions, including the TAM fraction. The partitioning in the
TAM fraction also did not explain the Cd AEs among the different types of prey used. These data strongly suggest that the application of TAM in predicting the trophic transfer of metals in whelks should be treated with caution. Given the extremely high metal AEs and the predominance of metals associated with the MRG and cellular debris in different prey, it is evident that metals were highly bioavailable to the predators regardless of their subcellular fates.

In our study, no relationship was observed between the AEs of Thais clavigera and their feeding rates, but the AEs were exceedingly low when the whelks fed at a much higher rate. There has been no report on metal assimilation as a function of food ingestion in marine predatory snails. The digestive process of metals in the whelks appears to be much longer than that found in marine suspension feeders such as bivalves. For example, the measured gut passage time of the metals was as long as $46 \mathrm{~h}$ in whelks, compared to between 3 and $24 \mathrm{~h}$ in mussels (Wang \& Fisher 1996). Such a long passage through the digestive tracts of the whelks may have prevented the establishment of a relationship between the AE and the feeding rate.

\section{Assimilation from oysters with different exposure regimes}

Many environmental factors may affect the subcellular metal distributions in organisms (Selck \& Forbes 2004). In our study, we used different exposure regimes to modify the subcellular metal distributions in the prey oysters Saccostrea glomerata, and examined whether these changes affected the metal AEs of Thais clavigera. Exposing the oysters to metals from different pathways resulted in a slight change in the metal distribution. For Ag, most metal was distributed in the insoluble fraction, but with further exposure, Ag redistributed in the oysters' digestive glands from the cellular debris fraction to the MRG fraction, whereas its distribution was rather constant in the other soft tissues. The AE was similar and no significant difference between each treatment was detected. For Cd, increasing distribution in the MRG fraction with increasing exposure time was similarly found, but more $\mathrm{Cd}$ was distributed in the soluble fraction as compared to Ag. There was, however, relatively small variation of metals distributed in the TAM fraction as a result of different exposure regimes of metals in the oysters (dissolved versus dietary radiolabeling; short versus long term radiolabeling). Consequently, there was no significant difference in the metal AEs among the different diet treatments (except for the Ag AEs from the digestive gland with short-term dietary exposure). 


\section{Metal assimilation from different subcellular fractions}

Previous studies have shown that metals bound to the MRG fraction are not trophically available to the bivalves and snails (Nott \& Nicolaidou 1993), and that metals bound to the MTLP and other enzymes are bioavailable to predators with very high AE (Ettajani et al. 2001, Wallace \& Luoma 2003). In this study, we isolated each subcellular fraction and fed the pure fraction to the whelks to directly quantify the metal AEs from each pure fraction.

In our experiments, there was no difference between the AEs of metals from the entire fraction except for the MRG fraction. Metals bound to the insoluble fraction of prey were also bioavailable to Thais clavigera with a very high $\mathrm{AE}$. One possible reason may be that the insoluble fraction also contained the organelle fraction. Wallace \& Luoma (2003) indicated that the organelle fraction was in fact available to the predator with an $\mathrm{AE}$ of $\sim 70 \%$; thus, the bioavailability of the insoluble fraction may potentially originate from the organelle fraction. Since the organelle fraction only contributed to between 20 and $30 \%$ of the total insoluble fraction, and assuming that its AE was $70 \%$, it only contributed 14 to $21 \%$ of the bioavailability of the insoluble fraction, which was in strong contrast to our results. Another possible source of metals from the insoluble fraction was the cellular debris fraction. A few studies have shown that $\mathrm{Cd}$ bound to the cellular debris fraction of the oligochaete Limnodrilus hoffmeisteri and $\mathrm{Cu}$ bound to the cellular debris of Nereis virens are bioavailable to the glass shrimp Palaemonetes pugio (with an AE of approximately $49 \%$ ) and polychaete Nereis diversicolor, respectively (Wallace \& Lopez 1997, Rainbow et al. 2004)

In experiments with the MRG fraction isolated directly from the different prey (oysters and snails), the results demonstrated that the whelks were able to assimilate metals appreciably from the MRG, even though the AEs for the snail MRG were lower when compared to the other subcellular fractions. To our knowledge, this is the first study that provides direct evidence of the bioavailability of MRG-bound metals to a marine predator. Several previous studies generally assumed that the predators were not able to assimilate metals bound to the insoluble granules. Given the high proportion of metals stored in granular form in many invetebrate species, the potential role played by the MRG in trophic transfer should be considered. One mechanism for the potential bioavailability of MRG-bound metals was the low gut $\mathrm{pH}$ of the predator. Nott \& Nicolaidou (1994) suggested that the MRG-bound $\mathrm{Ca}$ and Mn were available to the snail Nassarius reticulates primarily

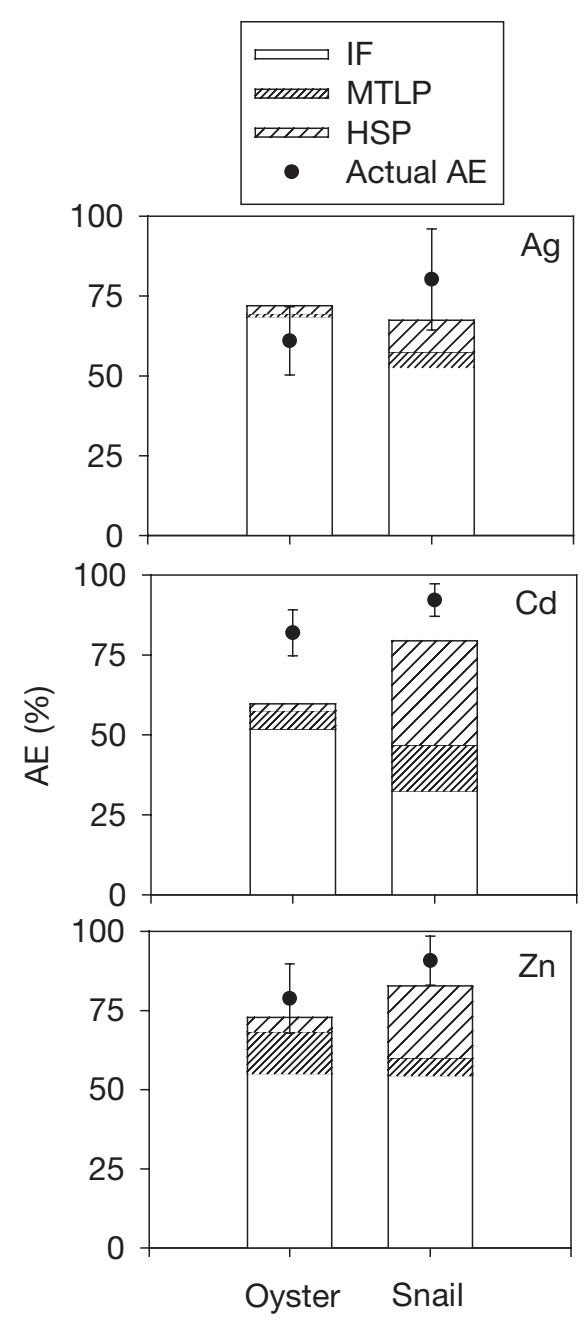

Fig. 9. Thais clavigera. Predicted assimilation efficiency (AE) of $\mathrm{Ag}, \mathrm{Cd}$ and $\mathrm{Zn}$ of whelks based on the measured AEs of different subcellular fractions. $\bullet$ : actual measured AEs for the whole tissues. Mean \pm SD $(n=8)$

because the low gut $\mathrm{pH}$ in this predatory snail may dissolute the carbonate granules, and calcium in the granules would become available and absorbed by the snails. The phosphate granules were insoluble in the gut environment of snails; thus, metals bound with the phosphate granules were not bioavailable to $N$. reticulates. Hence, there is a great need to examine the mechanisms underlying the high assimilation of metals associated with different metal rich granules, including the competition of $\mathrm{H}^{+}$for binding at the lowered $\mathrm{pH}$ conditions.

In addition, the enzymatic attack in the gut of predators may also play a role in the acquisition of MRGbound metals. Scheifler et al. (2003) found that terrestrial snails assimilated the 'nonavailable' $\mathrm{Cd}$ from soils as a result of the complexity of their digestive systems. 
During the digestive process, the ingested materials were attacked by numerous enzymes produced by the snails and some enzymatic activity was strong enough to dissociate the metals bound to the soil particles; thus, the gut $\mathrm{pH}$ and the enzymes of whelks may facilitate the uptake of the metals bound to the MRG. Furthermore, the form of granules should also be an important factor affecting the bioavailability of the metals associated with the granules (Nott \& Nicolaidou 1994).

In our study, about 70 to $80 \%$ of metals bound to the soluble fraction was available to Thais clavigera. The metal AEs from the HSP and the MTLP fractions were lower than other measurements (i.e. 100\%, Wallace \& Lopez 1996). Using our measurements of metal AEs from each pure subcellular fraction and the subcellular metal distribution, the overall AEs of whelks fed upon the non-fractionated tissues can be simply calculated by multiplying the percentage of that subcellular fraction and the AE of that specific fraction. The predicted metal $\mathrm{AE}$ is then compared with the direct measurement of metal AE (Fig. 9). In general, the prediction was rather comparable to the AE measured for the whole digestive gland of oysters

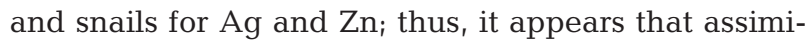
lation from each subcellular fraction may account for the overall assimilation of metals from prey tissues. Some fractions may be lost during the fractionation process, which may cause the underestimation of the quantity and the predicted AEs of Cd.

In conclusion, the whelk Thais clavigera had high metal AEs from different prey, and significant correlations between the metal AEs and the subcellular metal partitioning were documented in a few circumstances. The Cd assimilation was positively related to its partitioning in the MTLP fraction, and Zn assimilation was also positively related to the TAM fraction. These findings have implications in predicting the trophic transfer of metals along the marine food chain. Our study directly shows that metals bound with the MRG are bioavailable to whelks, suggesting that the MRG not only acts as a metal sink (sequestration) for the animals, but also can be potentially transferred to the next trophic level. With a mass balance method, the metal AEs from different prey can be predicted using the metal subcellular distribution and the AE of each single fraction. It is now necessary to study the interaction of metals in their trophic transfer to whelks, as well as extending our findings to other predators in marine food chains.

Acknowledgements. We thank the anonymous reviewers for their detailed comments. This work was supported by a Competitive Earmarked Research Grant from the Hong Kong Research Grants Council (HKUST6097/02M) to W.-X.W.

\section{LITERATURE CITED}

Abe N (1989) Interactions between carnivorous snails and their sessile animal prey at a rocky intertidal shore. Physiol Ecol Jpn 26:1-38

Abe N (1994) Growth and prey preference of the two forms in Thais clavigera (Kuester) under rearing. Venus Jpn J Malacol 53:113-118

Blackmore G (2000) Field evidence of metal transfer from invertebrate prey to an intertidal predator, Thais clavigera. Estuar Coast Shelf Sci 51:127-139

Blackmore G, Wang WX (2004) The transfer of cadmium, mercury, methylmercury, and zinc in an intertidal rocky shore food chain. J Exp Mar Biol Ecol 307:91-110

Chong K, Wang WX (2000) Assimilation of Cd, Cr, and Zn by the green mussel Perna viridis and the clam Ruditapes philippinarum. Environ Toxicol Chem 19:1660-1667

Clearwater SJ, Farag AM, Meyer JS (2002) Bioavailability and toxicity of dietborne copper and zinc to fish. Comp Biochem Physiol 132C:269-313

Ettajani H, Berthet B, Amiard JC, Chevolot L (2001) Determination of cadmium partitioning in microalgae and oyster: contribution to the assessment of trophic transfer. Arch Environ Contam Toxicol 40:209-221

Han BC, Jeng WL, Jeng MS, Kao LT, Meng PJ, Huang YL (1997) Rock-shells (Thais clavigera) as an indicator of As, $\mathrm{Cu}$, and $\mathrm{Zn}$ contamination on the Putai Coast of the blackfoot disease area in Taiwan. Arch Environ Contam Toxicol 32:456-461

Hung TC, Meng PJ, Han BC, Chuang A, Huang CC (2001) Trace metals in different species of mollusca, water and sediments from Taiwan coastal area. Chemosphere 44: 833-841

Klaassen CD, Liu J, Choudhuri S (1999) Metallothionein: an intracellular protein to protect against cadmium toxicity. Annu Rev Pharmacol Toxicol 39:267-294

Nott JA (1989) Metals in snails-metabolism and bioreduction. Mar Environ Res 28:201-205

Nott JA (1990) Transfer of metal detoxification along marine food chains. J Mar Biol Assoc UK 70:905-912

Nott JA, Nicolaidou A (1993) Bioreduction of zinc and manganese along a molluscan food chain. Comp Biochem Physiol 104A:235-238

Nott JA, Nicolaidou A (1994) Variable transfer of detoxified metals from snails to hermit crabs in marine food chains. Mar Biol 120:369-377

Nott JA, Bebianno MJ, Langston WJ, Ryan KP (1993) Cadmium in the gastropod Littorina littorea. J Mar Biol Assoc UK 73:655-665

Rainbow PS (1987) Heavy metals in barnacles. In: Southward AJ (ed) Barnacle biology. AA Balkema, Rotterdam, p 405-418

Rainbow PS (1993) The Significance of trace metal concentrations in marine invertebrates. In: Dallinger $\mathrm{R}$, Rainbow $\mathrm{P}$ (eds) Ecotoxicology of metals in invertebrates. Lewis Publishers, Boca Raton, FL, p 3-25

Rainbow PS, Geffard A, Jeantet AY, Smith BD, Amiard JC, Amiard-Triquet C (2004) Enhanced food-chain transfer of copper from a diet of copper-tolerant estuarine worms. Mar Ecol Prog Ser 271:183-191

Reinfelder JR, Fisher NS (1991) The assimilation of elements ingested by marine copepods. Science 251:794-796

Reinfelder JR, Fisher NS, Luoma SN, Nichols JW, Wang WX (1998) Trace element trophic transfer in aquatic organism: a critique of the kinetic model approach. Sci Total Environ 219:117-135

Roesijadi G (1992) Metallothionein in metal regulation and 
toxicity in aquatic animals. Aquat Toxicol 22:81-114

Roesijadi G (1996) Metallothionein and its role in toxic metal regulation. Comp Biochem Physiol 113:117-123

Scheifler R, Schwartz C, Echevarria G, De Vaufleury A, Badot P, Morel J (2003) 'Nonavailable' soil cadmium is bioavailable to snails: evidence from isotopic dilution experiments. Environ Sci Technol 37:81-86

Selck H, Forbes VE (2004) The relative importance of water and diet for uptake and subcellular distribution of cadmium in the deposit-feeding polychaete, Capitella sp I. Mar Environ Res 57:261-279

Tong LKY (1986) The feeding ecology of Thais clavigera and Morula musiva (Gastropoda: Muricidae) in Hong Kong. Asian Mar Biol 3:163-178

Viarengo A, Nott JA (1993) Mechanisms of heavy-metal cation homeostasis in marine-invertebrates. Comp Biochem Physiol 104:355-372

Wallace WG, Lopez GR (1996) Relationship between subcellular cadmium distribution in prey and cadmium trophic transfer to a predator. Estuaries 19:923-930

Wallace WG, Lopez GR (1997) Bioavailability of biologically sequestered cadmium and the implications of metal detoxification. Mar Ecol Prog Ser 147:149-157

Wallace WG, Luoma SN (2003) Subcellular compartmentalization of $\mathrm{Cd}$ and $\mathrm{Zn}$ in two bivalves. II. Significance of trophically available metal (TAM). Mar Ecol Prog Ser 257:125-137

Editorial responsibility: Otto Kinne (Editor-in-Chief), Oldendorf/Luhe, Germany
Wallace WG, Lopez GR, Levinton JS (1998) Cadmium resistance in an oligochaete and its effect on cadmium trophic transfer to an omnivorous shrimp. Mar Ecol Prog Ser 172: $225-237$

Wallace WG, Lee BG, Luoma SN (2003) Subcellular compartmentalization of $\mathrm{Cd}$ and $\mathrm{Zn}$ in two bivalves. I. Significance of metal-sensitive fraction (MSF) and biologically detoxified metal (BDM). Mar Ecol Prog Ser 249: 183-197

Wang WX (2002) Interaction of trace metals and different marine food chains. Mar Ecol Prog Ser 243:295-309

Wang WX, Fisher NS (1996) Assimilation of trace elements and carbon by the mussel Mytilus edulis: effects of food composition. Limnol Oceanogr 41:197-207

Wang WX, Fisher NS (1999) Delineating metal accumulation pathways for aquatic invertebrates. Sci Total Environ 237/238:459-472

Wang WX, Ke C (2002) Dominance of dietary intake of cadmium and zinc by two marine predatory snails. Aquat Toxicol 56:153-165

Xu Y, Wang WX (2001) Individual responses of trace-element assimilation and physiological turnover by the marine copepod Calanus sinicus to changes in food quantity. Mar Ecol Prog Ser 218:227-238

Xu Y, Wang WX (2002) The assimilation of detritus-bound metals by the marine copepod Acartia spinicauda. Limnol Oceanogr 47:604-610

Submitted: July 20, 2004; Accepted: November 2, 2004 Proofs received from author(s): January 14, 2004 